\title{
Tratamento de águas residuárias de suinocultura em reator UASB e filtro anaeróbio em série seguidos de filtro biológico percolador
}

\section{Treatment of swine wastewater in UASB reactor and anaerobic filter in series followed of trickling filter}

\author{
Rose Maria Duda \\ Engenheira Química. Doutora em Microbiologia Agropecuária pela Universidade Estadual “Júlio de Mesquita Filho" (UNESP), Campus de Jaboticabal. \\ Professora Assistente I da Faculdade de Tecnologia de Jaboticabal
}

\section{Roberto Alves de Oliveira}

Engenheiro Agrônomo e Tecnólogo em Construção Civil. Mestre em Agronomia pela UNESP, Câmpus de Jaboticabal. Doutor em Engenharia Civil - Hidráulica e Saneamento pela USP, Campus de São Carlos. Professor Doutor Assistente do Departamento de Engenharia Rural da UNESP, Campus de Jaboticabal

\section{Resumo}

Avaliou-se o desempenho de um reator anaeróbio de fluxo ascendente com manta de lodo (UASB) seguido de um filtro anaeróbio, instalados em série, com volume total de $300 \mathrm{~L}$ e $190 \mathrm{~L}$, respectivamente, no tratamento de águas residuárias de suinocultura. As cargas orgânicas volumétricas aplicadas no reator UASB foram de 12,4; 15,5; 23,2 e 26,3 g DQOtotal $(\mathrm{L} \text { d) })^{-1}$. Para o pós-tratamento do efluente do sistema anaeróbio em dois estágios utilizou-se um filtro biológico percolador com volume total de 250 L. O meio suporte utilizado nos filtros anaeróbio e biológico percolador foi composto por anéis de bambu. No sistema de tratamento anaeróbio e de pós-tratamento foram observadas eficiências médias de remoção de demanda química de oxigênio total (DQOtotal), sólidos suspensos totais (SST), nitrogênio total (NT), fósforo total (P-total), Cu e Zn de até 98, 99, 78, 84, 99 e 98\%, respectivamente.

Palavras-chave: digestão anaeróbia; matéria orgânica; metais; nutrientes.

\section{Abstract}

The performance of an upflow anaerobic sludge blanket (UASB) followed by the anaerobic filter, installed in series, was evaluated for the treatment of swine wastewater. The total volume of UASB and anaerobic filter were of $300 \mathrm{~L}$ and $190 \mathrm{~L}$, respectively. The organic load rate applied on the reactor UASB were of $12.4,15.5,23.2$ and $26.3 \mathrm{~g}$ total $\operatorname{COD}(\mathrm{L} \mathrm{d})^{-1}$. For the post-treatment of effluent the anaerobic system was used a trickling filter with total volume of $250 \mathrm{~L}$. The supports used in the anaerobic filter and trickling filter were composed by bamboo rings. The efficiencies of removal the chemical oxygen demand, total solids suspended, nitrogen, total phosphorus, Cu and Zn were of up to 98, 99, 78, 84, 99 and 98\%, respectively, for the anaerobic and aerobic treatment system.

Keywords: anaerobic digestion; organic matter; metal; nutrients. 


\section{Introdução}

A suinocultura é uma das atividades mais importantes do complexo agropecuário brasileiro e é predominantemente desenvolvida em pequenas propriedades rurais e em áreas com limitações topográficas para o estabelecimento de lavouras extensivas.

O sistema de produção em regime de integração foi o responsável pelo crescimento da suinocultura no Sul do Brasil (GARTNER; GAMA, 2005). Segundo a Pesquisa Agropecuária Municipal, o plantel brasileiro de suínos é estimado em 36 milhões de cabeças (IBGE, 2008), com equivalente populacional médio, em termos de demanda bioquímica de oxigênio $\left(\mathrm{DBO}_{5,20}\right)$ de 3,5 habitantes por suíno (MIRANDA, 2005). A suinocultura brasileira, apesar da sua posição privilegiada em termos de produção, ainda não universalizou os sistemas de tratamento de dejetos, causando impactos ambientais (GARTNER; GAMA, 2005).

A digestão anaeróbia é uma solução de baixo custo para o tratamento de águas residuárias com elevadas cargas orgânicas como as provenientes da suinocultura, com as vantagens da produção de biogás e da baixa produção de lodo (NDON; DAGUE, 1997; HWANG et al, 2009; SINGH; PRERNA, 2009) e da conservação dos nutrientes (AHN et al, 2006), além de ser uma solução apropriada para regiões de clima tropical (MARTINEZ et al, 2009), dentre outras.

Os reatores anaeróbios de fluxo ascendente com manta de lodo (UASB) estão sendo amplamente estudados em todo mundo, aplicados ao tratamento de esgoto sanitário (HALASLSHEH et al, 2005; ALVAREZ et al, 2008) e de águas residuárias agropecuárias (OLIVEIRA; FORESTI, 2004; SANCHEZ et al, 2005; SANTANA; OLIVEIRA, 2005). Sanchez et al (2005) afirmaram que ainda são limitados os trabalhos utilizando o reator UASB para o tratamento de águas residuárias de suinocultura. Karakashev et al (2008) citaram que não existem estudos com reatores UASB tratando águas residuárias de suinocultura com cargas orgânicas volumétricas (COV) superiores a $20 \mathrm{~g}$ DQOtotal ( $\mathrm{L} \mathrm{d})^{-1}$. No entanto, vários estudos recentes realizados no Brasil com reatores UASB, em escala piloto, tratando águas residuárias de suinocultura, com COV de 34,4 DQOtotal (L.d)-1 (RAMIRES, 2005) e COV de 26 g DQOtotal (L.d) $^{-1}$ (SANTANA, 2008), com eficiências de remoção de DQOtotal de $73 \%$ e de $86 \%$, respectivamente, indicam que os reatores UASB podem ser uma alternativa para o tratamento de águas residuárias de suinocultura com elevadas cargas orgânicas, dispensando o tratamento preliminar.

Segundo Kim et al. (2009) existem dificuldades no tratamento de águas residuárias de suinocultura em virtude da alta concentração de sólidos suspensos, prejudicando a hidrólise. O uso do processo anaeróbio em dois estágios (VAN HAANDEL; LETTINGA, 1994), com a hidrólise parcial da matéria orgânica particulada no primeiro reator e a conversão, no segundo reator, dos compostos solúveis formados no primeiro reator, pode atenuar o problema (HALASLSHEH et al., 2005; DUDA; OLIVEIRA, 2009).

O meio suporte contribui para o aumento do tempo de retenção de sólidos, favorecendo a população metanogênica e consequentemente aumenta a capacidade do filtro anaeróbio a resistir a choques orgânicos, às mudanças nas características do substrato e à presença de compostos tóxicos. Também pode contribuir para o entupimento do reator, em virtude da retenção de sólidos (RODGERS et al, 2008), por isso o uso conjunto de unidades com manta de lodo precedendo as com leito fixo pode contribuir para melhorar o desempenho de reatores anaeróbios.

Diversos estudos foram realizados com a aplicação do filtro anaeróbio de fluxo ascendente no tratamento de águas residuárias industriais e domésticas, utilizando com sucesso o meio suporte constituído por anéis de bambu (COUTO, 2003; CAMARGO, 2000; RAMIREZ et al, 2004). Segundo Camargo (2002), o bambu possui uma distribuição extensiva nas regiões sob climas tropicais e subtropicais, crescimento rápido e tem baixo custo nos países de terceiro mundo, comparado com materiais sintéticos.

Com a finalidade de promover equilíbrio entre as vantagens e desvantagens dos sistemas aeróbios e anaeróbios, pesquisas recentes combinam esses processos, em especial com uma primeira etapa anaeróbia seguida de um tratamento aeróbio complementar (RAMIREZ et al, 2003). O objetivo da combinação dos processos anaeróbios e aeróbios é aumentar a remoção de matéria orgânica, e também a remoção biológica do nitrogênio e fósforo, especialmente para águas residuárias, com concentrações de sólidos suspensos superiores a $4 \mathrm{~g} \mathrm{~L}^{-1}$, como as da suinocultura (SANCHEZ et al, 2005).

A aplicabilidade dos reatores anaeróbios é baseada em sua simplicidade operacional e baixo custo e, nesse sentido, é interessante que também as unidades de pós-tratamento apresentem as mesmas características. O filtro biológico percolador é uma tecnologia compacta, operacionalmente simples, de baixo consumo de energia e custo operacional. Vários trabalhos têm sido realizados com o objetivo de avaliar o comportamento de reatores UASB seguidos de filtros biológicos percoladores (FBP) tratando esgotos sanitários (SANTOS, 2005).

Neste trabalho, o projeto, a construção em escala piloto, e a operação do sistema de tratamento anaeróbio em dois estágios, constituído por um reator UASB seguido de um filtro anaeróbio de fluxo ascendente e a utilização do filtro biológico percolador para o pós-tratamento, tiveram como objetivo a avaliação do desempenho desse sistema no tratamento de águas residuárias de suinocultura, com altas concentrações de sólidos suspensos, quanto à eficiência de remoção de matéria orgânica, nutrientes, coliformes e a produção e qualidade do biogás. 
Material e métodos

\section{Descrição da unidade experimental e dos experimentos}

A unidade experimental (Figura 1) utilizada para o tratamento anaeróbio das águas residuárias de suinocultura foi constituída por um reator UASB (volume total de 300 L) seguido de um filtro anaeróbio de fluxo ascendente (volume total de 190 L), instalados em série. A unidade utilizada para o pós-tratamento do efluente produzido no sistema de tratamento anaeróbio foi um filtro biológico percolador (volume total de $250 \mathrm{~L}$ ) seguido de um decantador (150 L).

O meio suporte utilizado no filtro anaeróbio de fluxo ascendente e no filtro biológico percolador foram anéis de bambu com dimensões médias de 4,6; 2,5 e 0,25 cm de comprimento, diâmetro externo e espessura de parede, respectivamente. A área superficial específica e o índice de vazios médios dos anéis de bambu foram de $92,5 \mathrm{~m}^{2} . \mathrm{m}^{-3}$ e $75 \%$, respectivamente.
Para a obtenção do tempo de detenção hidráulica (TDH) e da COV no filtro anaeróbio e no filtro biológico percolador, foram utilizados os volumes úteis de 147 e 187 L, respectivamente. O reator UASB, o filtro anaeróbio, o filtro biológico percolador e o decantador foram construídos com tubos rígidos de policloreto de vinila (PVC) com seção transversal circular de $400 \mathrm{~mm}$.

Nos ensaios 1 e 2, os TDH aplicados nos reatores R1 e R2 foram de 24,0 e 11,7 h, respectivamente. Nos ensaios 3 e 4 os TDH aplicados no R1 e R2 foram reduzidos para 12,0 e 5,8 h, respectivamente (Tabela 1). O decréscimo do TDH de 24,0 para 12,0 h no reator UASB permitiu o aumento da velocidade ascensional de 0,10 para 0,20 m $\mathrm{h}^{-1}$, respectivamente (Tabela 1). Com a variação do TDH aplicados no Rl e das taxas de recirculação no filtro biológico percolador, os TDH aplicados no sistema de tratamento (UASB+filtro anaeróbio+filtro biológico percolador + decantador) foram 62,$7 ; 44,7 ; 31,3$ e 22,3 h, nos ensaios 1, 2, 3 e 4, respectivamente.

Nos ensaios 2 e 4 aplicaram-se taxas de recirculação (TR) no filtro biológico percolador de $200 \%$.

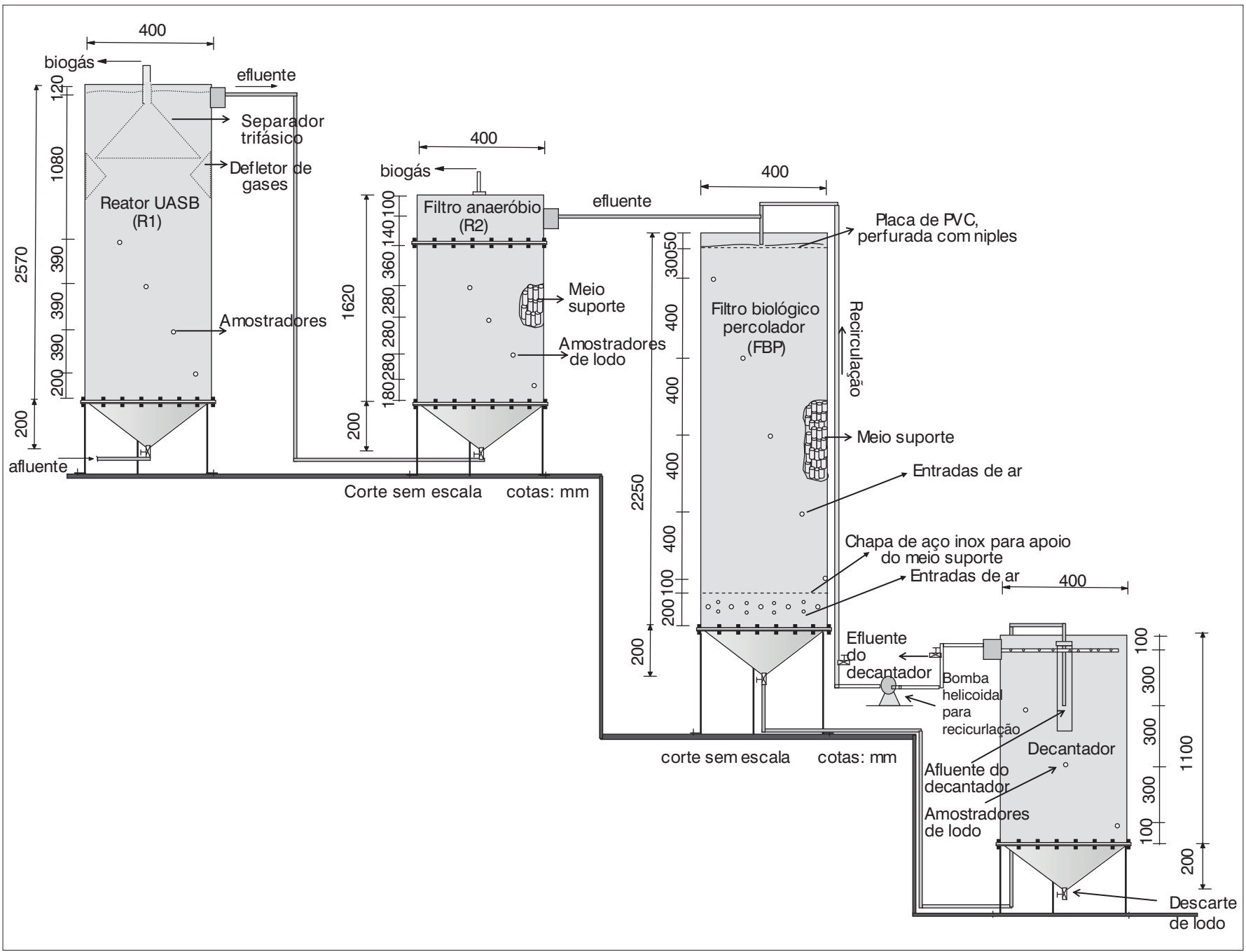

Figura 1 - Esquema da instalação experimental composta por um reator UASB seguido de um filtro anaeróbio de fluxo ascendente e do sistema de pós-tratamento composto pelo filtro biológico percolador e decantador. 
Nos ensaios 1 e 3 não foi realizada a recirculação do efluente no filtro biológico percolador. As cargas hidráulicas superficiais (Qs) aplicadas no okFBP e no decantador foram de 3,5; 10,6; 7,0;21,1 $\mathrm{m}^{3}$ $\left(\mathrm{m}^{2} . \mathrm{d}\right)^{-1}$ e de 2,$6 ; 7,9 ; 5,2,15,9 \mathrm{~m}^{3}\left(\mathrm{~m}^{2} . \mathrm{d}\right)^{-1}$, nos ensaios $1,2,3$ e 4 , respectivamente (Tabela 1 ).

\section{Coleta de amostras e análises laboratoriais}

Foram coletadas amostras compostas do afluente e dos efluentes, a cada hora, das 8 às 12 horas e mantidas resfriadas à temperatura de $4^{\circ} \mathrm{C}$. Nas amostras compostas foram determinados o $\mathrm{pH}$, a alcalinidade total (AT), a alcalinidade parcial (AP), as demandas químicas de oxigênio total (DQOtotal), das frações dissolvida (DQOdiss) e dos sólidos suspensos (DQOss); sólidos suspensos totais (SST), sólidos suspensos voláteis (SSV), nitrogênio total (NT) (N-orgânico+Namoniacal+N-nitrato+N-nitrito), fósforo total (P-total), $\mathrm{Cu}$ e Zn, duas vezes por semana. Todas as determinações foram realizadas conforme descrito por APHA, AWWA e WPCF (1998). As temperaturas médias do ar foram obtidas pela Estação Agroclimatológica, do Departamento de Ciências Exatas da UNESP, Jaboticabal. O volume de biogás produzido foi monitorado diariamente por meio de medidas em gasômetros (SANTANA; OLIVEIRA, 2005), e a composição do biogás foi analisada semanalmente em cromatografia gasosa, conforme descrito por APHA, AWWA, WPCF (1998).

\section{Resultados e discussão}

As alterações na composição do afluente, com valores médios de DQOtotal de $12.338 ; 15.570 ; 13.168$ e 11.596 mg DQOtotal..$^{-1}$ e de SST de $6.950 ; 9.730 ; 8.130$ e 7.630 mg SST.L ${ }^{-1}$, nos ensaios $1,2,3$ e 4 (Tabela 2), respectivamente, e com coeficientes de variação (c.v.) acima de 39\%, ocorreram em virtude de variações na idade e manejo dos animais, durante a coleta diária das águas residuárias, nas instalações de confinamento de suínos na fase de terminação.
Os valores médios da DQOss do afluente corresponderam a 88 91; 87 e 90 \% da DQO total, nos ensaios 1, 2, 3 e 4, respectivamente, indicando a predominância de sólidos suspensos orgânicos.

As COV aplicadas no R1 e R2 foram de 12,4; 15,5; 26,3 e 23,2 g DQOtotal (L.d)-1 e de 4,4; 6,3; 5,5 e 2,9 g DQOtotal (L.d) ${ }^{-1}$, nos ensaios 1, 2, 3 e 4, respectivamente (Tabela 2). Segundo Chernicharo (2007), as COV típicas aplicadas em reatores UASB tratando esgoto doméstico são inferiores a 15 gDQOtotal (L.d) $)^{-1}$, embora COV de até 45 g DQOtotal (L.d) ${ }^{-1}$ tenham sido aplicadas com sucesso. Os valores de COV para filtros anaeróbios podem ultrapassar 20 g DQOtotal (L.d) ${ }^{-1}$, mas segundo Couto (1993), situam-se normalmente na faixa de 1 a 10 g DQOtotal (L.d) $)^{-1}$

Os valores médios de DQOtotal, DQOdiss, SST e SSV no efluente do decantador diminuíram acentuadamente, comparando-se com o afluente do reator UASB e foram de 500; 630; 478 e $326 \mathrm{mg}$ DQOtotal.L $L^{-1} ; 290 ; 349 ; 259$ e 186 mg DQOdiss.L.-1; 257; 172; 111

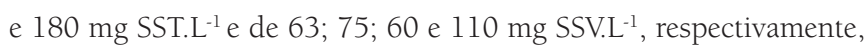
nos ensaios 1, 2, 3 e 4 .

As eficiências de remoção de DQOtotal no R1 foram de 80; 82; 86 e $91 \%$ nos ensaios 1, 2, 3 e 4, respectivamente. As maiores eficiências de remoção de DQOtotal, DQOdiss, DQOss e SST no R1, de $91 ; 83 ; 91 ; 93$ e 95\%, respectivamente, ocorreram no ensaio 4, com o TDH de 12 h, COV de 23,2 g DQOtotal (L.d) $)^{-1}$ e temperatura média do ar de $22^{\circ} \mathrm{C}$, favorecidas pelo longo período de adaptação do lodo a altas COV e as maiores velocidades superficiais nos ensaios 3 e 4 (Tabela 2). Ramirez et al (2002) obtiveram valores de eficiência de remoção de DQOtotal similares as observadas no Rl, de $82,5 \%$, em um sistema de tratamento anaeróbio combinando reator UASB e filtro anaeróbio no tratamento de águas residuárias da suinocultura. O sistema era composto por um reator UASB (volume de 3,6 L) operado com TDH de 4 h, seguido de um filtro anaeróbio (volume de 13 L) operado com TDH de 14 h. O meio suporte utilizado no filtro anaeróbio foi constituído de cilindros de plástico.

Tabela 1 - Condições operacionais do sistema de tratamento anaeróbio em dois estágios, com o reator UASB seguido de um filtro anaeróbio de fluxo ascendente seguido do filtro biológico percolador (FBP) para o pós-tratamento, nos ensaios 1, 2, 3 e 4

\begin{tabular}{|c|c|c|c|c|c|c|c|c|c|}
\hline \multirow{2}{*}{\multicolumn{2}{|c|}{ Parâmetros }} & \multicolumn{2}{|c|}{ Ensaio 1} & \multicolumn{2}{|c|}{ Ensaio 2} & \multicolumn{2}{|c|}{ Ensaio 3} & \multicolumn{2}{|c|}{ Ensaio 4} \\
\hline & & Média & c.v. & Média & c.v. & Média & c.v. & Média & c.v. \\
\hline \multicolumn{2}{|c|}{ Duração do ensaio (dias) } & 74 & - & 50 & - & 55 & - & 56 & - \\
\hline \multicolumn{2}{|c|}{ Temperatura média do ar $\left({ }^{\circ} \mathrm{C}\right)$} & 25 & 10 & 24 & 7 & 23 & 6 & 22 & 10 \\
\hline \multirow{4}{*}{$\mathrm{TDH}(\mathrm{h})$} & UASB (R1) & 24 & - & 24 & - & 12 & - & 12 & - \\
\hline & Filtro anaeróbio (R2) & 11,7 & - & 11,7 & - & 5,8 & - & 5,8 & - \\
\hline & FBP & 15 & - & 5 & - & 7,5 & - & 2,5 & - \\
\hline & Decantador & 12 & - & 4 & - & 6 & - & 2 & - \\
\hline \multirow{2}{*}{$V\left(m \cdot h^{-1}\right)$} & UASB & 0,1 & - & 0,1 & - & 0,2 & - & 0,2 & - \\
\hline & Filtro anaeróbio (R2) & 0,13 & - & 0,13 & - & 0,26 & - & 0,26 & - \\
\hline Taxa recirculação (\%) & FBP & 0 & - & 200 & - & 0 & - & 200 & - \\
\hline Qs $\left(m^{3}\left(m^{2} d\right)^{-1}\right)$ & FBP & 3,5 & - & 10,6 & - & 7 & - & 21,1 & - \\
\hline
\end{tabular}

c.v.: coeficiente de variação (\%); TDH: tempo de detenção hidráulica; v: velocidade superficial de escoamento; Qs: taxa de aplicação hidráulica superficial (vazão/área) 
As eficiências médias de remoção da DQOtotal; DQOdiss, DQOss, SST e SSV no R2 diminuíram do ensaio 1 para o ensaio 4. O decréscimo nas eficiências de remoção no R2 pode ter ocorrido em virtude do arraste de sólidos do lodo. As maiores eficiências de remoção de sólidos suspensos durante o ensaio 1, podem ter ocorrido pela retenção no leito fixo. Segundo Couto (1993), as possíveis causas de entupimento e consequente arraste de sólidos do filtro anaeróbio são a presença de sólidos suspensos, a precipitação de carbonato de cálcio e a obstrução biológica.

As eficiências médias de remoção de DQOtotal para o sistema de tratamento anaeróbio (R1+R2) foram de 91; 83; 89 e 90\%, nos ensaios 1, 2, 3 e 4, respectivamente (Figura 2A). A inclusão do filtro anaeróbio de fluxo ascendente no segundo estágio contribuiu para o aumento nos valores médios das eficiências de remoção da DQO e dos sólidos suspensos, exceto no ensaio 4. As eficiências de remoção de DQOdiss aumentaram nos ensaios 3 e 4, com a diminuição do TDH, em virtude da maior velocidade superficial, melhorando a transferência de massa da fração solúvel no lodo granular e floculento dos interstícios e no biofilme anaeróbio. Os aumentos nas eficiências de remoção de DQOtotal, DQOss e sólidos suspensos, com a inclusão do segundo estágio no sistema de tratamento anaeróbio também foram observados por Diamantis e Aivasidis (2007) e Duda e Oliveira (2009).

No ensaio 2, com a aplicação de COV de 5,8 g DQOtotal (L.d)-1 e taxas de aplicação hidráulica superficial (Qs) de 10,6 $\mathrm{m}^{3}\left(\mathrm{~m}^{2} \cdot \mathrm{d}\right)^{-1}$ no FBP, foram observadas as maiores eficiências de remoção de DQOtotal, DQOss e SST de 64; 81 e 79\%, respectivamente, no sistema de pós-tratamento, composto pelo FBP e o decantador. O sistema de pós-tratamento contribuiu para o aumento das eficiências de remoção de DQOtotal, DQOss, SST e SSV do sistema de tratamento anaeróbio em dois estágios durante os ensaios. Não se observaram acréscimos nas remoções de DQOdiss com a inclusão do sistema de pós-tratamento.

Foram observadas eficiências de remoção de 94,9; 97,8; 93,3 e 96,7\% e de 97,8; 97,9; 98,5 e 95,7\% para a DQOtotal e SST (Figura 2B), respectivamente, no sistema de tratamento anaeróbio seguido do pós-tratamento, com TDH de 62,7; 44,7; 31,3 e 22,3 h (Tabela 1). Nos ensaios 2 e 4, com a recirculação de 200\% no FBP, foram obtidas as maiores remoções de DQOtotal, para o sistema de tratamento ( $\mathrm{R} 1+\mathrm{R} 2+\mathrm{FBP}+$ decantador). Isso indica que a recirculação no FBP foi necessária para melhorar a sua estabilidade e manter as eficiências de remoção de DQOtotal, SST e SSV acima de 93\%, com coeficientes de variação (c.v.) de 4\%. A recirculação é um elemento muito importante no projeto de filtros biológicos, e é essencial para despejos concentrados, pois, além de aumentar a eficiência de remoção da DBO, impede também que os filtros fiquem secos, e reduz a temperatura do despejo em função do número de passagens do líquido através do leito percolado (BELÉM, 1996).

Com o sistema de pós-tratamento foi possível obter remoções de matéria orgânica similares, com variações de vazão do afluente de até 2,8 vezes e com taxa de recirculação no FBP de $200 \%$, indicando tratar-se de alternativa econômica de alta eficiência e robustez.

Tabela 2 - Valores médios da COV nos reatores, DQOtotal, DQOdiss, SST, SSV dos afluentes e efluentes, e respectivos coeficientes de variação (c.v. em $\%$ ), no sistema de tratamento composto pelo reator UASB (R1), filtro anaeróbio de fluxo ascendente (R2), filtro biológico percolador (FBP) e decantador, nos ensaios 1, 2, 3 e 4.

\begin{tabular}{|c|c|c|c|c|c|c|c|c|c|}
\hline Parâmetros & & Ensaio 1 & c.v. & Ensaio 2 & c.v. & Ensaio 3 & c.v. & Ensaio 4 & c.v \\
\hline \multirow{3}{*}{$\begin{array}{l}\text { COV } \\
\left.\text { [g DQOtotal (L. d) }{ }^{-1}\right]\end{array}$} & $\mathrm{R} 1$ & 12,4 & 71 & 15,5 & 64 & 26,3 & 75 & 23,2 & 44 \\
\hline & $\mathrm{R} 2$ & 4,4 & 71 & 6,3 & 55 & 5,5 & 45 & 2,9 & 59 \\
\hline & Decantador & 1,2 & 54 & 4,7 & 71 & 3,2 & 47 & 5,0 & 20 \\
\hline \multirow{4}{*}{$\begin{array}{l}\text { DQOtotal } \\
\left(\mathrm{mg} \cdot \mathrm{L}^{-1}\right)\end{array}$} & Afluente & 12338 & 71 & 15570 & 64 & 13168 & 75 & 11596 & 44 \\
\hline & $\mathrm{R} 1$ & 2134 & 71 & 3089 & 108 & 1325 & 45 & 702 & 59 \\
\hline & $\mathrm{R} 2$ & 872 & 84 & 2062 & 67 & 1127 & 46 & 685 & 44 \\
\hline & Decantador & 500 & 69 & 630 & 54 & 478 & 34 & 326 & 27 \\
\hline \multirow{4}{*}{$\begin{array}{l}\text { DQOdiss } \\
\left(\mathrm{mg} \cdot \mathrm{L}^{-1}\right)\end{array}$} & Afluente & 1520 & 53 & 1366 & 52 & 1658 & 36 & 1056 & 44 \\
\hline & $\mathrm{R} 1$ & 336 & 39 & 337 & 68 & 302 & 32 & 166 & 38 \\
\hline & $\mathrm{R} 2$ & 307 & 43 & 355 & 56 & 251 & 34 & 149 & 43 \\
\hline & Decantador & 290 & 59 & 349 & 58 & 259 & 27 & 186 & 27 \\
\hline \multirow{4}{*}{$\begin{array}{l}\text { SST } \\
\left(m g \cdot L^{-1}\right)\end{array}$} & Afluente & 6950 & 51 & 9730 & 43 & 8130 & 39 & 7630 & 44 \\
\hline & $\mathrm{R} 1$ & 1291 & 105 & 1540 & 116 & 836 & 56 & 274 & 35 \\
\hline & $\mathrm{R} 2$ & 600 & 107 & 870 & 80 & 613 & 91 & 480 & 80 \\
\hline & Decantador & 257 & 147 & 172 & 48 & 111 & 57 & 180 & 146 \\
\hline \multirow{4}{*}{$\begin{array}{l}\text { SSV } \\
\left(\mathrm{mg} \cdot \mathrm{L}^{-1}\right)\end{array}$} & Afluente & 3250 & 72 & 5810 & 71 & 5030 & 36 & 4160 & 74 \\
\hline & $\mathrm{R} 1$ & 499 & 130 & 1020 & 147 & 615 & 81 & 163 & 56 \\
\hline & $\mathrm{R} 2$ & 303 & 133 & 310 & 118 & 330 & 94 & 210 & 51 \\
\hline & Decantador & 63 & 93 & 75 & 90 & 60 & 62 & 110 & 156 \\
\hline
\end{tabular}

COV: carga orgânica volumétrica; DQOtotal: demanda química de oxigênio total; DQOdiss: demanda química de oxigênio da fração dissolvida; SST: sólidos suspensos totais; SSV: sólidos suspensos voláteis 
Os valores médios do percentual de $\mathrm{CH}_{4}$ no biogás, respectivamente, nos ensaios 1, 2, 3 e 4 foram de 81,5; 80,8; 83,0 e 81,8 \% no R1 e de 74,$4 ; 79,2 ; 82,2$ e 81,8 \% no R2. Os maiores valores médios do percentual de $\mathrm{CH}_{4}$ no biogás foram observados no ensaio 3, com a aplicação da maior COV no R1, de 26,3 g DQOtotal (L.d)-1 (Tabela 3).

Os valores da produção volumétrica de $\mathrm{CH}_{4}$ média, no $\mathrm{Rl}$ e $\mathrm{R} 1+\mathrm{R} 2$ foram de 0,$544 ; 0,688 ; 0,772$ e $0,816 \mathrm{~m}^{3} \mathrm{CH}_{4}\left(\mathrm{~m}^{3} \text { reator } \mathrm{d}\right)^{-1}$ e de 0,$432 ; 0,552 ; 0,562$ e $0,574 \mathrm{~m}^{3} \mathrm{CH}_{4}\left(\mathrm{~m}^{3} \text { reator } \mathrm{d}\right)^{-1}$, para as $\mathrm{COV}$ aplicadas nos ensaios 1, 2, 3 e 4, respectivamente. Com o aumento da COV observaram-se acréscimos na produção volumétrica de metano no R1 e R1+R2, no entanto, acréscimos menores que os aumentos da COV. As produções específicas de metano para o sistema $\mathrm{R} 1+\mathrm{R} 2$ foram de 0,081;0,082; 0,075 e 0,067 $\mathrm{m}^{3} \mathrm{CH}_{4}$ (kg DQOtotal removida) ${ }^{-1}$, nos ensaios 1, 2, 3 e 4, respectivamente (Tabela 3). Essa tendência também foi observada por Fernandes e Oliveira (2006), que atribuíram a menor eficiência de conversão dos compostos orgânicos a metano com o aumento da COV.

Os valores médios do pH do afluente variaram de 5,9 a 6,1. Os valores médios de $\mathrm{pH}$ observados no efluente do R1 e R2 variaram de 7,1 a 7,4 e de 7,1 a 7,5, nos ensaios 1, 2, 3 e 4, respectivamente. Segundo Chernicharo (2007), a faixa ótima de $\mathrm{pH}$ para o desenvolvimento das metanogênicas é de 6,6 a 7,4; embora possa se conseguir estabilidade na formação de metano numa faixa de 6,0 a 8,0. Os valores médios de $\mathrm{pH}$ no efluente do FBP e do decantador foram de 7,8; 8,$0 ; 7,9 ;$ e 7,8 e de 8,$0 ; 8,0 ; 7,9$ e 7,8, respectivamente, nos ensaios 1, 2, 3 e 4. A faixa de pH para que ocorra a nitrificação é de 7,5 a 8,6 (METCALF e EDDY, 2003), indicando que não houve limitação para esse parâmetro no FBP.
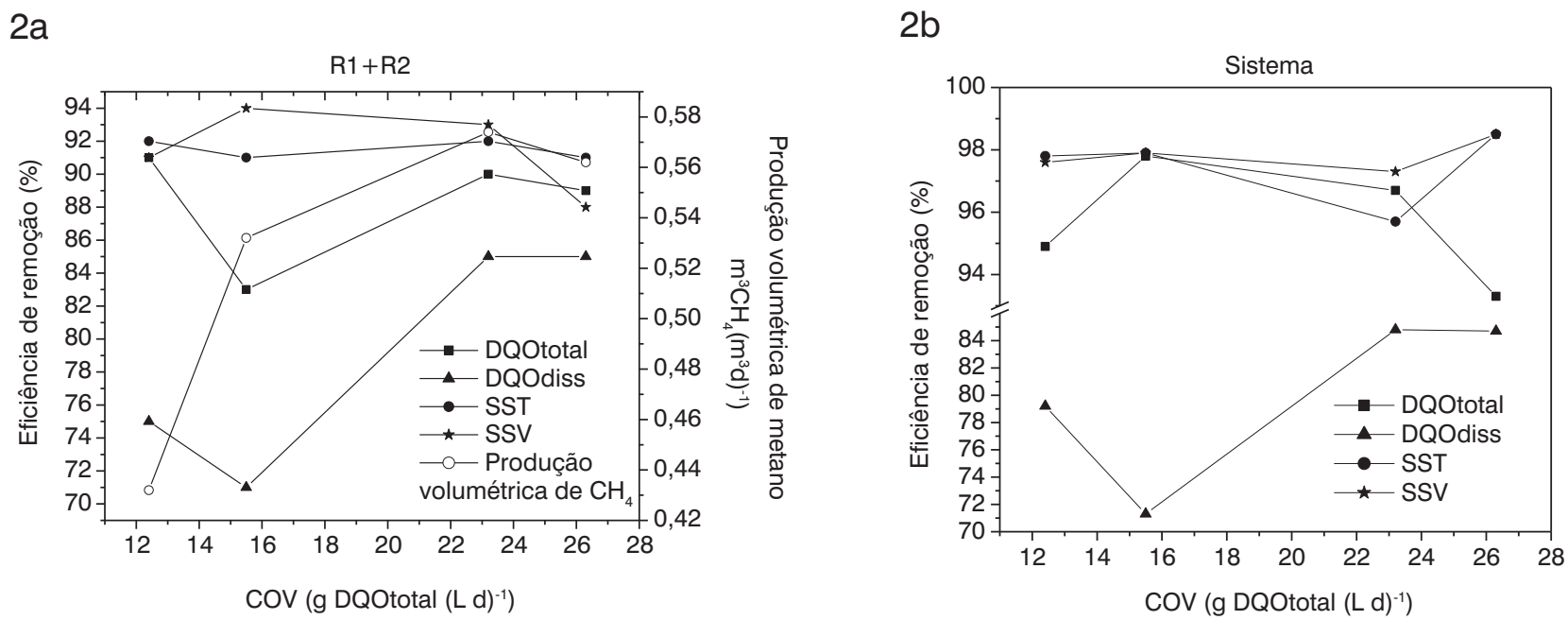

Figura 2 - Eficiências médias de remoção de DQOtotal, DQOdiss, SST, SSV e produção volumétrica de metano obtidos no reator UASB e filtro anaeróbio de fluxo ascendente em série (R1 + R2) (a) e do sistema (R1+R2+FBP+D) (b), em função da COV aplicada no R1.

Tabela 3 - Valores médios e respectivos coeficientes de variação (c.v. em \%) da percentagem de metano $\left(\mathrm{CH}_{4}\right)$ no biogás, das produções diárias e volumétricas de $\mathrm{CH}_{4}$ e das produções específicas de $\mathrm{CH}_{4}$ em relação à DQO removida, obtidos durante a operação do sistema de tratamento anaeróbio em dois estágios, nos ensaios 1, 2, 3 e 4

\begin{tabular}{llccccccccc} 
Parâmetros & & Ensaio 1 & c.v. & Ensaio 2 & c.v. & Ensaio 3 & c.v. & Ensaio 4 & c.v \\
\hline $\mathrm{CH}_{4}(\%)$ & $\mathrm{R} 1$ & 81,5 & 2 & 80,8 & 3 & 83,0 & 2 & 81,8 & 3 \\
& $\mathrm{R} 2$ & 74,4 & 12 & 79,2 & 5 & 82,2 & 5 & 81,8 & 3 \\
& $\mathrm{R} 1$ & 0,544 & 37 & 0,688 & 41 & 0,772 & 35 & 0,816 & 30 \\
\hline $\begin{array}{l}\text { Produção volumétrica de } \mathrm{CH}_{4} \\
\left(\mathrm{~m}^{3} \mathrm{CH}_{4}\left(\mathrm{~m}^{3} \text { reator d) }\right)^{-1}\right)\end{array}$ & $\mathrm{R} 2$ & 0,200 & 77 & 0,251 & 45 & 0,127 & 52 & 0,108 & 51 \\
& $\mathrm{R} 1+\mathrm{R} 2$ & 0,432 & 31 & 0,532 & 36 & 0,562 & 33 & 0,574 & 31 \\
& $\mathrm{R} 1$ & 0,080 & 78 & 0,072 & 72 & 0,069 & 102 & 0,062 & 79 \\
\hline $\left.\begin{array}{l}\text { Produção específica de } \mathrm{CH}_{4} \\
\left(\mathrm{Nm}^{3} \mathrm{CH}_{4}(\mathrm{~kg} \mathrm{DQO} \text { removida) }\right.\end{array}{ }^{-1}\right)$ & $\mathrm{R} 2$ & 0,13 & 83 & 0,11 & 97 & 0,13 & 79 & 0,12 & 114 \\
& $\mathrm{R} 1+\mathrm{R} 2$ & 0,081 & 72 & 0,082 & 81 & 0,075 & 104 & 0,067 & 83
\end{tabular}


Os maiores valores de AT nos efluentes dos reatores R1 e R2, de 874 a 1138 mg.L-1 e de 860 a 1260 mg.L.-1, respectivamente, do que os presentes nos seus afluentes, de 646 a $896 \mathrm{mg} . \mathrm{L}^{-1}$, indicam que houve incremento de alcalinidade, proporcionando capacidade de tampão aos reatores. O aumento da alcalinidade total (AT) ocorreu em virtude do acréscimo na concentração de bicarbonato, como pode ser observado por meio dos aumentos dos valores médios da alcalinidade parcial (AP) nos efluentes do R1, para 624 a 847 mg.L.-1, e do R2, para 650 a $915 \mathrm{mg} . \mathrm{L}^{-1}$, em relação a do afluente, de 85 a $288 \mathrm{mg} . \mathrm{L}^{-1}$. A alcalinidade intermediária (AI), proporcionada pelos ácidos graxos voláteis, diminuiu de 560 a 633 mg. $L^{-1}$ no afluente para 203 a 255 mg. $L^{-1}$ e 188 a 345 mg. L $^{-1}$ nos efluentes do R1 e do R2, indicando o consumo desses ácidos, principalmente no Rl

O consumo médio de AT e AP para a nitrificação no sistema de pós-tratamento composto pelo FBP e decantador foram de 429; 586; 253 e 372 mg. $L^{-1}$ e de 339; 417; 206 e 258 mg. L $^{-1}$, nos ensaios 1, 2, 3 e 4, respectivamente. Os maiores consumos de AT foram observados no ensaio 2, com a aplicação de COV de 5,8 g DQOtotal (L.d) ${ }^{-1}$ e taxa de aplicação hidráulica superficial (Qs) de 10,6 $\mathrm{m}^{3}\left(\mathrm{~m}^{2} . \mathrm{d}\right)^{-1}$ no FBP. Nos ensaios 2 e 4, com a utilização da recirculação, observaram-se os maiores consumos de AT e AP e as maiores concentrações de N-nitrato e N-nitrito nos efluentes do FBP

Os valores de nitrogênio na forma de nitrato e nitrito observados no efluente do FBP foram de 32, 40, 29 e $42 \mathrm{mg} . \mathrm{L}^{-1}$ e de 24, 38, 28 e $31 \mathrm{mg} . \mathrm{L}^{-1}$, respectivamente, nos ensaios 1, 2, 3 e 4. No efluente do decantador foram observados valores de nitrato e nitrito inferiores aos observados no efluente do FBP, além de aumento da AT, o que pode ter ocorrido em virtude da produção de alcalinidade proporcionada pela desnitrificação heterotrófica Segundo Metcalf e Eddy (2003), são produzidas 3,57 mg de $\mathrm{CaCO}_{3}\left(\mathrm{mg} \mathrm{NO}_{3}\right)^{-1}$ na desnitrificação.

No efluente do FBP e do decantador foram observadas concentrações de oxigênio dissolvido (OD) de 5,1; 3,9; 3,7 e 5,1 mg..-1e de 4,$3 ; 2,9 ; 3,0$ e 4,1 mg. $\mathrm{L}^{-1}$, respectivamente, nos ensaios 1, 2, 3 e 4. Segundo Metcalf e Eddy (2003), a desnitrificação pode ocorrer na presença de baixas concentrações de oxigênio dissolvido $\left(0,5 \mathrm{mg} \cdot \mathrm{L}^{-1}\right)$. Isso porque a concentração de oxigênio no interior do biofilme pode ser menor que no meio líquido, propiciando a desnitrificação nas camadas internas do biofilme.

As eficiências médias de remoção de nitrogênio total (NT) no sistema de tratamento anaeróbio $(\mathrm{R} 1+\mathrm{R} 2)$ foram de 55; 52; 65 e $59 \%$, nos ensaios 1, 2, 3 e 4, respectivamente (Figura 3a). Com o sistema de pós-tratamento $(\mathrm{R} 1+\mathrm{R} 2+\mathrm{FBP}+\mathrm{D})$, as eficiências médias de remoção de NT aumentaram para $68 ; 57 ; 78$ e $68 \%$, com os TDH de 62,7; 44,7; 31,3 e 22,3 h, nos ensaios 1, 2, 3 e 4, respectivamente (Figura 3b). As eficiências médias de remoção de NT observadas neste trabalho aproximaram-se das obtidas por Bernet et al (2000), de 85 a 91\%, tratando águas residuárias de suinocultura com SST variando de 2,8 a 18 g..-1 , em reator sequencial em batelada anaeróbio e aeróbio, em série.

As eficiências médias de remoção de P-total no Rl foram de 42; 64; 51 e 68\%, nos ensaios 1, 2, 3 e 4, respectivamente. No sistema de tratamento $\mathrm{R} 1+\mathrm{R} 2$ as eficiências de remoção foram de 45; 53; 49 e 66\%, nos ensaios 1, 2, 3 e 4, respectivamente. O R2 não contribuiu para o aumento da eficiência de remoção de P-total do sistema de tratamento $(\mathrm{R} 1+\mathrm{R} 2)$, exceto no ensaio 1 . As maiores eficiências de remoção de P-total no reator UASB podem ser atribuídas à retenção de sólidos no lodo do reator e à possibilidade de remoção por precipitação do fósforo. As maiores eficiências de remoção de P-total no R1 de 68\% foram observadas no ensaio 4, com a aplicação de COV de 23,2 g DQOtotal (L.d) ${ }^{-1}$ e com a estimativa do maior tempo de retenção de sólidos (TRS), de 58 dias (Tabela 4).

A remoção de P-total no FBP pode ter ocorrido também pela precipitação de sais de fosfato sobre o meio suporte (bambu), em virtude da observação na microscopia eletrônica de varredura de minerais aderidos à superfície interna dos anéis de bambu, compostos principalmente por $\mathrm{P}, \mathrm{Mg}$ e $\mathrm{Ca}$, conforme microanálise de energia dispersiva de raio $\mathrm{X}$ (EDX).

As eficiências médias de remoção de P-total no sistema de tratamento anaeróbio seguido do pós-tratamento aumentaram para $72 ; 75 ; 71$ e 84\%, nos ensaios 1, 2, 3 e 4, respectivamente. Os valores médios de eficiência de remoção de P-total obtidos neste trabalho foram superiores aos observados por Deng et al (2007), de $70,6 \%$, no tratamento de águas residuárias de suinocultura com DQOtotal de $6.561 \mathrm{mg}$ DQOtotal. $\mathrm{L}^{-1}$, em reator UASB seguido de reator em batelada aeróbio.

As maiores eficiências médias de remoção de Cu e Zn, de 97\%, no sistema de tratamento $\mathrm{R} 1+\mathrm{R} 2$, ocorreram no ensaio 4 (Figura 3a). A adoção do sistema de pós-tratamento permitiu aumentar as eficiências médias de remoção de Cu e Zn para 91 a 99 \% e para 96 a $98 \%$, respectivamente, no sistema de tratamento $\mathrm{R} 1+\mathrm{R} 2+\mathrm{FBP}+\mathrm{D}$ (Figura 3b).

No efluente do decantador foram observadas concentrações médias de 0,$1 ; 0,1 ; 0,07$ e 0,004 mg. $\mathrm{L}^{-1}$ para o $\mathrm{Cu}$ e de 0,1;0,2; 0,08 e 0,08 mg. $\mathrm{L}^{-1}$ para o $\mathrm{Zn}$, nos ensaios $1,2,3$ e 4 , respectivamente. Portanto, o efluente do decantador atendeu aos limites máximos de lançamento de efluentes, de 1,0 mg. $\mathrm{L}^{-1}$ para o $\mathrm{Cu}$ e de 5,0 mg. $\mathrm{L}^{-1}$ para o Zn, estabelecidos pela Resolução Conama n ${ }^{\circ}$ 357/2005 (BRASIL, 2005).

Os valores médios das taxas de carregamento orgânico no lodo (TCL) no reator UASB e no filtro anaeróbio foram de 0,$82 ; 2,04$; 2,20; 2,21 e 1,71 g DQOtotal (g SV d)-1 e 0,29; 0,53; 0,36; 0,43 e 0,21 g DQOtotal ( $\mathrm{g} \mathrm{SV} \mathrm{d})^{-1}$, respectivamente, nos ensaios 1, 2, 3 e 4, respectivamente (Tabela 4). A TCL, durante o regime permanente, pode atingir, de acordo com o tipo de água residuária a ser tratada, 
$3 a$

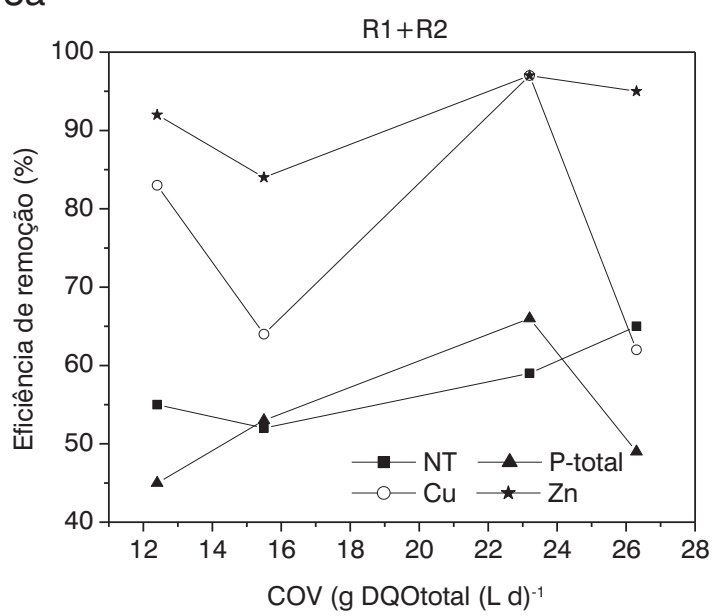

$3 b$

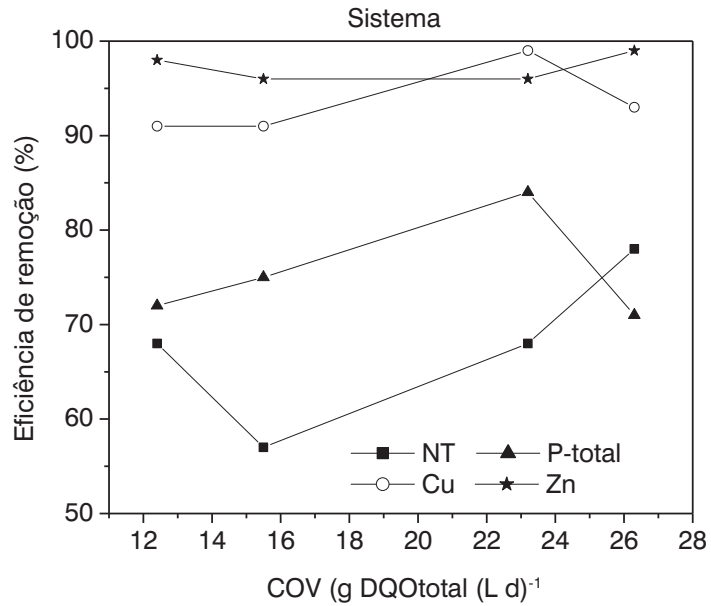

Figura 3a e 3b - Eficiências médias de remoção (em \%) de NT, P-total, Cu e Zn obtidas no reator UASB e no filtro anaeróbio de fluxo ascendente em série (R1 + R2), e no sistema (R1+R2+FBP+D), em função da COV aplicada no R1.

Tabela 4 - Valores médios e os coeficientes de variação (c.v.) da taxa de carregamento do lodo (TCL) no reator UASB (R1) e no filtro anaeróbio (R2) em série durante 0 ensaio.

\begin{tabular}{|c|c|c|c|c|c|c|c|c|c|}
\hline \multirow{2}{*}{\multicolumn{2}{|c|}{ Reatores }} & \multicolumn{2}{|c|}{ Ensaio 1} & \multicolumn{2}{|c|}{ Ensaio 2} & \multicolumn{2}{|c|}{ Ensaio 3} & \multicolumn{2}{|c|}{ Ensaio 4} \\
\hline & & & c. v. $(\%)$ & & c. v. (\%) & & c. v. (\%) & & c. v. $(\%)$ \\
\hline \multirow{2}{*}{ R1 } & $\mathrm{TCL}$ & 2,04 & 45 & 2,20 & 18 & 2,21 & 33 & 1,71 & 52 \\
\hline & TRS & 32 & 82 & 36 & 57 & 16 & 62 & 58 & 71 \\
\hline \multirow{2}{*}{$\mathrm{R} 2$} & TCL & 0,53 & 86 & 0,36 & 53 & 0,43 & 41 & 0,21 & 72 \\
\hline & TRS & 53 & 79 & 71 & 53 & 15 & 64 & 23 & 78 \\
\hline
\end{tabular}

c.v.: coeficiente de variação; TRS: tempo de retenção de sólidos (d); TCL: taxa de carregamento orgânico no lodo [gDQO / (g .SV. d)].

valores em torno de 2,0 g DQOtotal (g SV d) ${ }^{-1}$ (Chernicharo, 2007). Verificou-se que a aplicação de cargas orgânicas no lodo acima das recomendadas, nos ensaios 1, 2 e 3 não prejudicaram a estabilidade do processo em termos de $\mathrm{pH}$ e ácidos voláteis totais e consequentemente o desempenho para remoção a de DQO, sólidos suspensos e produção de metano.

O tempo de retenção de sólidos (TRS) foi de 32, 36, 16 e 58 d e de 53, 71, 15 e 23 d, no R1 e R2, respectivamente, nos ensaios 1, 2, 3 e 4, respectivamente. Portanto o TRS nos ensaios 1, 2, 3 e 4 foi superior a $10 \mathrm{~d}$, que é o mínimo recomendado para o processo metanogênico na temperatura de $35^{\circ} \mathrm{C}$, segundo Ndon e Dague (1997).

\section{Conclusões}

As eficiências médias de remoção de DQOtotal e SST no sistema de tratamento anaeróbio foram superiores a 83 e 91\%, respectivamente, para COV variando de 12,4 a 26,3 g DQOtotal (L.d) ${ }^{-1}$, indicando que os reatores UASB podem ser uma alternativa econômica e robusta para o tratamento de águas residuárias de suinocultura com elevadas cargas orgânicas, dispensando o tratamento preliminar.

O pós-tratamento composto pelo filtro biológico percolador e decantador, para as COV e taxas de aplicação superficial aplicadas, contribuiu para o aumento nas eficiências de remoção de DQO, sólidos suspensos, NT, P-total, Cu e Zn atingindo valores de 93 a 98\%, 96 a 99\%, 57 a 78\%, 71 a 84\%, 91 a 99\% e de 96 a 98\%, respectivamente. Isso indica que o sistema de tratamento anaeróbio em dois estágios, com o reator UASB e o filtro anaeróbio, seguido do filtro biológico percolador e decantador podem ser viáveis para o tratamento de águas residuárias de suinocultura com altas eficiências de remoção de matéria orgânica e nutrientes, com cargas orgânicas volumétricas elevadas.

\section{Agradecimentos}

À Fundação de Amparo à Pesquisa do Estado de São Paulo (Fapesp) e à Tigre S. A. pelo apoio financeiro. 


\section{Referências}

AHN, J.H.; DOA, T.H.; KIMB, S.D.; HWANGA, S. The effect of calcium on the anaerobic digestion treating swine wastewater. Biochemical Engineering, v. 30, n. 1, p. 33-60, 2006.

ALVAREZ, J.A.; ARMSTRONG, E.; GOMEZ, M.; SOTO, M. Anaerobic treatment of low-strength municipal wastewater by a two-stage pilot plant under psychrophilic conditions. Bioresource Technology, Barking, v. 99, n. 6, p. 7051-7062, 2008.

APHA/AWWA/WPCF. Standard methods for the examination of water and wastewater. 20 ${ }^{\text {th }}$, Washington, 1998. $1.569 \mathrm{p}$.

BELÉM, B.D. Pós-tratamento de esgoto sanitário através de filtro biológico com taxas variáveis. 1996. 101f. Dissertação (Mestrado em Hidráulica e Saneamento) - Escola de Engenharia de São Carlos, Universidade de São Paulo, São Carlos, 1996.

BERNET, N.; DELGENES, N.; AKUNNA, J.C.; DELGENES, J.P. Combined anaerobic-aerobic SBR for the treatment of piggery wastewater. Water Research, New York, v. 34, n. 2, p. 611-619, 2000.

BRASIL. Ministério do Meio Ambiente. CONAMA. Resolução n 357 , de 17 de março de 2005. Dispõe sobre a classificação dos corpos de águas e diretrizes ambientais para o seu enquadramento, bem como estabelece as condições e padrões de lançamento de efluentes, e dá outras providências. Brasília, BR, 2005. 23 p.

CAMARGO, S.A.R. Filtro anaeróbio com enchimento em bambu para o tratamento de esgotos sanitários: avaliação da partida e operação. 194 p. 2000. Dissertação (Mestrado em Engenharia Civil, área de concentração de Saneamento e Ambiente). Universidade Estadual de Campinas, Campinas, 2000.

CHERNICHARO, C.A.L. Reatores anaeróbios: princípios do tratamento biológico em águas residuárias. 2.ed. Belo Horizonte: DESA/UFMG, 2007. 359 p.

COUTO, L.C.C. Filtro anaeróbio com bambu para tratamento de esgotos domésticos. 1993. Dissertação (Mestrado em Engenharia Civil) Faculdade de Engenharia Civil, Universidade Estadual de Campinas, Campinas, 1993. 99 p.

DENG, L.; CHEN, C.A.I.C.; CHEN, Z. The treatment of pig slurry by a fullscale anaerobic-adding raw wastewater-intermittent aeration process. Biosystems Enginnering, v. 98, n. 1, p. 327-334, 2007.

DIAMANTIS, V.; AIVASIDIS, A. Comparison of single- and two-stage UASB reactors used for anaerobic treatment of synthetic fruit wastewater. Enzyme and Microbial Technology, v. 42, n. 1, p. 6-10, 2007.

DUDA, R.M.; OLIVEIRA, R.A. Reatores anaeróbios operados em batelada sequencial, seguidos de lagoas de polimento, para o tratamento de águas residuárias de suinocultura. Parte I: produção de metano e remoção de $\mathrm{DQO}$ e de sólidos suspensos. Engenharia Agrícola, Jaboticabal, v. 29, n. 1, p. 122-134, 2009.

FERNANDES, G.F.; OLIVEIRA, R.A. Desempenho de processo anaeróbio em dois estágios (reator compartimentado seguido de reator UASB) para tratamento de águas residuárias de suinocultura, Engenharia agrícola, Jaboticabal, v. 26, n.1, p. 243-256, 2006.

GARTNER, I.R.; GAMA, M.L.S. Avaliação multicriterial dos impactos ambientais da suinocultura no Distrito Federal: um estudo de caso. Organizações Rurais e Agrícolas, Lavras, v. 7, n. 2, p. 148-161, 2005

HWANG, K.; SONG, M.; KIM, W.; HWANG, S. Effects of prolonged starvation on methanogenic population dynamics in anaerobic digestion of swine wastewater. Bioresource Technology, 2009. Barking, in press, doi:10.1016/j.biortech.2009.03.070.

INSTITUTO BRASILEIRO DE GEOGRAFIA E ESTATÍSTICA (IBGE). Fundação Instituto Brasileiro De Geografia E Estatística. Disponível em: < http://www.sidra.ibge.gov.br/ > . Acesso em: 15 de mar. 2008.

KIM, W.; HWANG, K.; SHIN, S.G.; LEE, S. HWANG, S. Effect of high temperature on bacterial community dynamics in anaerobic acidogenesis using mesophilic sludge inoculum. Bioresource Technology, 2009. Barking, in press, doi:10.1016/j.biortech.2009.03.029.

MARTINEZ, J.; Dabert, P.; Barrington, S.; Burton, C. Livestock waste treatment systems for environmental quality, food safety, and sustainability. Bioresource Technology, 2009. Barking, in press, doi:10.1016/j.biortech.2009.02.038.

MIRANDA, C.R. de. Avaliação de estratégias para sustentabilidade da suinocultura. 2005. Tese (Engenharia Ambiental) - Universidade Federal de Santa Catarina, Florianópolis, 2005. 264 p.

METCALF; EDDY. Wastewater Engineering: treatment, disposal and reuse. New York: McGraw-Hill, 2003. 1334 p.

NDON, U.J.; DAGUE, R.R. Effects of temperature and hydraulic retention time on anaerobic sequencing batch reactor in the treatment of lowstrength wastewater. Water Research, Oxford, v. 31, n. 10, p. 2455-2466, 1997.

OLIVEIRA, R.A. de; FORESTI, E. Balanço de massa de reatores anaeróbios de fluxo ascendente com manta de lodo (UASB) tratando aguas residuarias de suinocultura. Engenharia Agrícola, Jaboticabal, v. 24, n. 3, p. 807-820, 2004.

RAMIREZ, O.P.; ANTUNES, R.M.; QUADRO, M.S.; KOETZ, P.R. Filtro anaeróbio utilizado como pós-tratamento de um reator anaeróbio de fluxo ascendente (UASB) para dejetos de suinocultura. Revista Brasileira de Agrociência, Pelotas, v. 10, n. 3, p.339-346, 2004.

RAMIREZ, O.P.; QUADRO, M.S., ANTUNES, R.M., KOETZ, P.R. Influência da carga orgânica volumétrica aplicada no pós-tratamento de águas residuárias de suinocultura por contactores biológicos rotatórios e reator anóxico. Revista Brasileira de Agrociência, Pelotas, v.9, n. 4, p.413-420, 2003.

RAMIREZ, O.P.; QUADRO, M.S.; KOETZ, P.R. Avaliação de um sistema combinado de UASB-Filtro no tratamento anaeróbio de águas residuárias de suinocultura. Olam-Ciência \& Tecnologia, Rio Claro, v. 2, n. 2, 2002. 
RAMIRES, R. dél ARCO. Produção de metano e remoção de matéria orgânica, nutrientes e microrganismos patogênicos em reatores anaeróbios de fluxo ascendente com manta de lodo (UASB) em dois estágios tratando águas residuárias de suinocultura. 2005. Dissertação (Mestrado em Microbiologia Agropecuária) - Faculdade de Ciências Agrárias e Veterinárias, Universidade Estadual Paulista, Jaboticabal, 2005. $136 \mathrm{p}$.

RODGERS, M.; PAOR de D.; CLIFFORD, E. Dairy wastewater treatment using a horizontal flow biofilm system. Journal of Environmental Management, Galway, Ireland, v. 86, p. 114-120, 2008.

SANTANA, A. M. Avaliação de sistema composto por reatores anaeróbios e aeróbio para tratamento de águas residuárias de suinocultura.. 2008. Tese (Doutorado em Microbiologia Agropecuária) - Faculdade de Ciências Agrárias e Veterinárias, Universidade Estadual Paulista, Jaboticabal, 2008. $261 \mathrm{p}$.

SANTANA, A. M. de; OLIVEIRA, R. A. deDesempenho de reatores anaeróbios de fluxo ascendente com manta de lodo em dois estágios tratando águas residuárias de suinocultura. Engenharia Agrícola, Jaboticabal, v. 25, n. 3, p. 817-830, 2005

SANCHEZ, E.P.; BORJA, R.; TRAVIESO, I.; Mart, A.; Colmenarejo, M.F. Effect of organic loading rate on the stability, operational parameters and performance of a secondary upflow anaerobic sludge bed reactor treating piggery waste. Bioresource Technology, Barking, v. 96, n. 1, p. 335-344, 2005.

SANTOS, A.S.P. Avaliação de desempenho de um filtro biológico percolador com diferentes meios suportes plásticos. 2005. Dissertação (Mestrado em Ciência em Engenharia Civil) - Universidade Federal do Rio de Janeiro, Rio de Janeiro, 2005. 91 p.

SINGH, S.P.; PRERNA, P. Review of recent advances in anaerobic packedbed biogas reactors. Renewable and Sustainable Energy Reviews, v. 13 n. 1, p. 1569-1575, 2009.

VAN HAANDEL, A.C.; LETTINGA, G. Anaerobic sewage treatment: a pratical guide for regions with a hot climate. Chichester: John Wiley and Sons, 1994. 226 p. 